\title{
Resistance to QoI Fungicides in Ascochyta rabiei from Chickpea in the Northern Great Plains
}

\author{
K. A. Wise, Department of Plant Pathology, North Dakota State University, Fargo 58105; C. A. Bradley, Depart- \\ ment of Crop Sciences, University of Illinois, 1102 S. Goodwin Ave., Urbana 61801; and J. S. Pasche and \\ N. C. Gudmestad, Department of Plant Pathology, North Dakota State University, Fargo 58105
}

\begin{abstract}
Wise, K. A., Bradley, C. A., Pasche, J. S., and Gudmestad, N. C. 2009. Resistance to QoI fungicides in Ascochyta rabiei from chickpea in the Northern Great Plains. Plant Dis. 93:528-536.

Ascochyta blight, caused by Ascochyta rabiei (teleomorph: Didymella rabiei), is an important fungal disease of chickpea (Cicer arietinum). A monitoring program was established in 2005 to determine the sensitivity of $A$. rabiei isolates to the QoI (strobilurin) fungicides azoxystrobin and pyraclostrobin. A total of 403 isolates of A. rabiei from the Northern Great Plains and the Pacific Northwest were tested. Ninety-eight isolates collected between 2005 and 2007 were tested using an in vitro spore germination assay to determine the effective fungicide concentration at which $50 \%$ of conidial germination was inhibited $\left(\mathrm{EC}_{50}\right)$ for each isolate-fungicide combination. A discriminatory dose of $1 \mu \mathrm{g} / \mathrm{ml}$ azoxystrobin was established and used to test 305 isolates from 2006 and 2007 for in vitro QoI fungicide sensitivity. Sixty-five percent of isolates collected from North Dakota in 2005, 2006, and 2007 and from Montana in 2007 were found to exhibit a mean 100-fold decrease in sensitivity to both azoxystrobin and pyraclostrobin when compared to sensitive isolates, and were considered to be resistant to azoxystrobin and pyraclostrobin. Under greenhouse conditions, QoI-resistant isolates of A. rabiei caused significantly higher amounts of disease than sensitive isolates on azoxystrobin- or pyraclostrobin-amended plants. These results suggest that disease control may be inadequate at locations where resistant isolates are present.
\end{abstract}

Ascochyta blight, caused by the fungus Ascochyta rabiei (Pass.) Labr. (teleomorph: Didymella rabiei (Kovacheski) v. Arx.), is an important disease of chickpea (Cicer arietinum L.) throughout the world (22). A. rabiei can infect chickpea at all stages of plant phenology and can cause over $50 \%$ yield reduction under conditions favorable for disease development $(13,17)$. Within the United States and Canada, Ascochyta blight epidemics are common, making it the most important disease of chickpea in these regions $(8,13)$.

Management of Ascochyta blight requires an integrated approach that includes crop rotation and burial of debris from the previous crop to reduce overwintering inoculum. Chickpea cultivars with moderate levels of resistance are available for use, but none have complete resistance to the dominant pathotype of $A$. rabiei in the United States $(8,10,32)$. Current resistance levels are often insufficient to prevent disease development and economic loss in the

Corresponding author: N. C. Gudmestad E-mail: neil.gudmestad@ndsu.edu

Current address of K. A. Wise: Department of Botany and Plant Pathology, Purdue University, West Lafayette, IN 47907.

Accepted for publication 29 January 2009.

doi:10.1094/PDIS-93-5-0528

(C) 2009 The American Phytopathological Society
Northern Great Plains (15). Fungicide seed treatments are used to control seed-borne A. rabiei (29), and several applications of foliar fungicides often are required in the Northern Great Plains of the United States and in the Canadian prairies to manage Ascochyta blight (7).

Chlorothalonil and maneb are fungicides with multi-site mode of action and broadspectrum protectant activity, and are typically applied prior to flowering to delay the onset of Ascochyta blight. However, once blight symptoms are present, applications of chlorothalonil or maneb alone do not control disease, forcing producers to employ fungicides with both pre- and postinfection modes of action $(11,13)$. Prior to 2007 , only two classes of fungicide chemistry with post-infection activity were registered for control of Ascochyta blight on chickpea in the United States: the quinone outside inhibitor (QoI) class (azoxystrobin and pyraclostrobin) and the carboximide class (boscalid). In 2002, the United States Environmental Protection Agency (EPA) granted a section 18 emergency chickpea to control Ascochyta blight in North Dakota. In 2003, azoxystrobin, boscalid, and pyraclostrobin were granted full section 3 registrations on chickpea in the United States. In 2007, prothioconazole, a sterol-demethylation inhibitor (DMI) fungicide, was registered for the control of Ascochyta blight. All of these fungicides have a single-site mode of exemption for use of azoxystrobin on action and are at risk for fungicide resistance development.

Currently, of these fungicides, QoI fungicides play an important role in management of Ascochyta blight. These fungicides inhibit mitochondrial respiration by binding to the center of the Qo site of the cytochrome $\mathrm{bc}_{1}$ complex (complex III) on the positive side of the inner mitochondrial membrane $(4,5)$. While this class of fungicides is extremely effective at managing a broad range of diseases on many crops, the site-specific mode of action may increase the potential for selection of resistant mutants of fungal pathogens (3). QoI fungicide resistance was first reported in Erysiphe graminis on wheat just 2 years after the class was registered for use in Europe (4).

Since 1998, field resistance to QoI compounds has been documented for important pathogens of horticulture and field crops $(1-4,14-16,19,22,25,30,31,35)$. Until recently, the mechanism of resistance has been attributed to single-point mutation resulting in amino acid substitution at one of two positions in the cytochrome $b$ gene. In the majority of pathogens, glycine is replaced by alanine at codon 143 (G143A), resulting in expression of resistant phenotypes $(3,5,12,14,16,18,19,34)$, while a second mutation results in a phenylalanine to leucine change on amino acid 129 (F129L), and is found in Pyricularia grisea (19), Pyrenophora tritici-repentis and Pyrenophora teres (27), and Alternaria solani (23). In 2007, a third cytochrome $b$ mutation resulting in a glycine to arginine change at amino acid position 137 was reported. This G137R mutation has recently been observed in two isolates of Pyrenophora tritici-repentis (27). The type of mutation present in a fungal population greatly influences the level of disease control obtained with QoI fungicide applications $(14,23,27)$. Fungal isolates with the G143A mutation typically have complete resistance, meaning that applications of all QoI fungicides are ineffective at controlling disease (14). The presence of the F129L or G137R mutation results in reduced sensitivity and levels of disease control obtained by QoI fungicide applications $(19,23,24,27)$.

Since the registration of QoI fungicides for use on chickpea in 2003, fungicide applications in North Dakota for Ascochyta blight control have relied almost 
exclusively on fungicides within the QoI class. Applications of fungicides with postinfection activity typically begin when disease is first observed in a field, and continue on a 10- to 14-day schedule until conditions are no longer favorable for disease development. In the Northern Great Plains, favorable environmental conditions can often persist throughout the growing season, and in some instances up to six sequential applications of QoI fungicides have been made to a chickpea field in a single growing season. Ascochyta blight is a polycyclic disease (29), and the continuous use of QoI fungicides in this region increases the frequency of selection and pathogen population exposed to this fungicide class during a growing season, potentially contributing to the development of fungicide resistance. QoI-resistant isolates of A. rabiei have been identified through in vitro testing in Canada since $2004(7,15)$, and the risk of fungicide resistance development in the Northern Great Plains populations is high. In 2006, anecdotal reports from chickpea producers in western North Dakota indicated that applications of QoI fungicides were not providing adequate control of Ascochyta blight.

Because of the nearly exclusive use of this chemistry, the limited number of fungicide chemistries with different modes of action, the identification of resistance in Canada, and anecdotal reports of reduced fungicide efficacy in North Dakota, QoI resistance development for A. rabiei has been identified as a major concern in the Northern Great Plains region. Baseline sensitivity of A. rabiei to azoxystrobin and pyraclostrobin was determined in a previous study (33), facilitating the development of a regional fungicide sensitivity monitoring program. The overall objectives of this study were to (i) determine if a shift in sensitivity to QoI fungicides has occurred in the North Dakota A. rabiei population, (ii) establish an in vitro single discriminatory dose testing method using azoxystrobin, and (iii) determine if isolates exhibiting in vitro QoI fungicide resistance were controlled less by QoI fungicides in vivo using greenhouse experiments.

\section{MATERIALS AND METHODS}

Collection of $A$. rabiei isolates. Isolates of $A$. rabiei were obtained from chickpea production fields in North Dakota receiving QoI fungicide applications during 2005, 2006, or 2007. Chickpea plants with symptoms of Ascochyta blight were sampled on a cross-diagonal transect pattern (' $\mathrm{X}$ '), with samples taken at set intervals of approximately $15 \mathrm{~m}$. Isolates also were obtained from diseased chickpea in research plots located at North Dakota State University Research Extension Centers in Hettinger, Minot, and Williston, ND. Disease samples were bulked by field or research plot and returned to the laboratory for isolation. Additional isolates were recovered from infected plant material from South Dakota and Nebraska from Martin Draper (South Dakota State University, Brookings) and Robert Harveson (University of Nebraska, Scottsbluff) in 2005 and Mary Burrows in Montana (Montana State University, Bozeman) in 2006 and 2007. Isolates were obtained from Idaho and Washington in 2005 from the A. rabiei culture collection of Weidong Chen at the United States Department of AgricultureAgricultural Research Service (USDAARS) in Pullman, WA.

Isolates of A. rabiei tested for in vitro fungicide sensitivity screening were obtained by cutting symptomatic chickpea stems into 2- to 3-cm sections. Stem sections were placed in a $95 \%$ ethanol solution for $1 \mathrm{~min}$, followed by a rinse in sterile distilled water (SDW) for $1 \mathrm{~min}$ followed by $0.5 \% \mathrm{NaOCl}$ solution for 1 min, and rinsed again for $1 \mathrm{~min}$ in SDW. Sterilized stem sections were air-dried in a laminar flow hood for $30 \mathrm{~s}$ on autoclaved paper towels and placed on potato dextrose agar (PDA) (Difco Laboratories, Detroit, MI) amended with $10 \mathrm{mg} /$ liter streptomycin sulfate (Sigma-Aldrich, St. Louis, MO) in petri plates. Conidial and mycelial growth was observed from plated stem sections after 3 to 6 days of incubation at $20^{\circ} \mathrm{C}$ under a diurnal cycle of cool white fluorescent light ( $12 \mathrm{~h}$ light followed by 12 $\mathrm{h}$ dark). The presence of $A$. rabiei was confirmed by microscopic observation of conidia at $\times 100$ magnification. An individual conidium from each sterilized stem section was considered a distinct isolate, and was incubated on fresh PDA under the conditions previously described. Singlespore isolates were stored for short-term use (up to 6 months) by removing three to four $0.25-\mathrm{cm}$-diameter plugs of agar covered with sporulating growth from each 14-day-old culture and placing plugs in a 1.5 -ml centrifuge tube with $1 \mathrm{ml}$ of SDW. Tubes were sealed with Parafilm and stored at $4^{\circ} \mathrm{C}$. Isolates were preserved for long-term storage as conidia and mycelia on sterile filter paper at $-20^{\circ} \mathrm{C}(33)$.

In vitro fungicide sensitivity assay. Fungicide sensitivity to azoxystrobin and pyraclostrobin was determined in vitro for 98 isolates of A. rabiei collected from 2005 to 2007 using previously published methods (33) (Table 1). Stock solutions of technical grade formulations of azoxystrobin (97.6\% active; Syngenta Crop Protection, Greensboro, NC) and pyraclostrobin (99\% active; BASF Corporation, Research Triangle Park, NC) were prepared at concentrations of $100 \mathrm{mg} / \mathrm{ml}$ and diluted serially in acetone. Fungicide sen-

Table 1. Collection information and results of in vitro Ascochyta rabiei isolate sensitivity assays to azoxystrobin and pyraclostrobin in 2005, 2006, and 2007

\begin{tabular}{|c|c|c|c|}
\hline \multirow{3}{*}{$\begin{array}{l}\text { Collection location } \\
\text { by county }\end{array}$} & \multirow[b]{3}{*}{ Number of isolates } & \multicolumn{2}{|c|}{$\mathrm{EC}_{50}(\mu \mathrm{g} / \mathrm{ml})^{\mathrm{a}}$} \\
\hline & & Azoxystrobin & Pyraclostrobin \\
\hline & & Range & Range \\
\hline \multicolumn{4}{|l|}{2005} \\
\hline \multicolumn{4}{|l|}{ North Dakota } \\
\hline Cass & 2 & $0.033-0.034$ & $0.0032-0.0039$ \\
\hline Foster & 5 & $0.030-0.039$ & $0.0019-0.0101$ \\
\hline Ward & 7 & $0.026-19.0$ & $0.0035-0.5473$ \\
\hline Total & 14 & $0.026-19.0$ & $0.0019-0.5473$ \\
\hline South Dakota & 1 & 0.032 & 0.0037 \\
\hline Nebraska & 1 & 0.033 & 0.0043 \\
\hline Idaho & 1 & 0.033 & 0.0044 \\
\hline Washington & 2 & $0.031-0.032$ & $0.0077-0.0182$ \\
\hline Overall total & 19 & $0.026-19.0$ & $0.0019-0.5473$ \\
\hline \multicolumn{4}{|l|}{2006} \\
\hline \multicolumn{4}{|l|}{ North Dakota } \\
\hline Cass & 4 & $3.81-5.82$ & $0.2100-2.730$ \\
\hline Foster & 3 & $0.030-16.2$ & $0.0027-2.400$ \\
\hline McClean & 5 & $5.87-29.0$ & $2.380-3.233$ \\
\hline Mountrail & 8 & $3.22-25.7$ & $0.3470-3.090$ \\
\hline Renville & 10 & $5.68-16.5$ & $0.3710-3.145$ \\
\hline Ward & 17 & $0.032-32.4$ & $0.0029-2.970$ \\
\hline Williams & 1 & 5.94 & 0.5900 \\
\hline Total & 48 & $0.030-37.7$ & $0.0027-3.233$ \\
\hline Montana & 1 & 0.032 & 0.0032 \\
\hline Overall total & 49 & $0.030-37.7$ & $0.0027-3.233$ \\
\hline \multicolumn{4}{|l|}{2007} \\
\hline \multicolumn{4}{|l|}{ North Dakota } \\
\hline Adams & 1 & 3.40 & 2.927 \\
\hline Hettinger & 1 & 0.032 & 0.0030 \\
\hline McClean & 6 & $3.30-31.9$ & $2.740-3.549$ \\
\hline Mountrail & 5 & $0.029-28.4$ & $0.0034-3.613$ \\
\hline Williams & 17 & $0.032-32.4$ & $0.0030-3.780$ \\
\hline Total & 30 & $0.029-32.4$ & $0.0030-3.780$ \\
\hline
\end{tabular}

${ }^{a}$ Fungicide sensitivity was determined by calculating the mean effective fungicide concentration in hibiting spore germination by $50 \%$ of the nontreated control $\left(\mathrm{EC}_{50}\right.$ value; $\left.\mu \mathrm{g} / \mathrm{ml}\right)$. 
sitivity was determined for 2005 and 2006 isolates by evaluating $A$. rabiei conidial germination on PDA amended with 0 , $0.001,0.01,0.1,1,10$, and $100 \mu \mathrm{g} / \mathrm{ml}$ of each fungicide. Sensitivity of isolates collected in 2007 was determined on azoxystrobin-amended PDA at concentrations of $0,0.01,0.1,1,10$, and $100 \mu \mathrm{g} / \mathrm{ml}$ and pyraclostrobin-amended PDA at 0, 0.001, $0.1,1$, and $10 \mu \mathrm{g} / \mathrm{ml}$. Salicylhydroxamic acid (SHAM; Sigma-Aldrich) was dissolved in methanol and added to all fungicide-amended media at a concentration $100 \mu \mathrm{g} / \mathrm{ml}$ to minimize the effects of the alternative oxidative pathways that some fungi use to overcome QoI fungicide toxicity in fungicide sensitivity assays in vitro $(4,9,33)$. A. rabiei is able to use this alternative pathway in the presence of QoI fungicides, and SHAM has been determined to have no effect on conidial germination (33). In all experiments, the $0 \mu \mathrm{g} / \mathrm{ml}$ treatment served as a control and was amended with $100 \mu \mathrm{g} / \mathrm{ml}$ SHAM, $1 \mathrm{ml}$ of acetone, and $1 \mathrm{ml}$ of methanol per liter.

A. rabiei isolates in all experiments were prepared using previously reported methods (33). Briefly, a conidial suspension was obtained by adding sterile $0.05 \%$ Tween 20 (Sigma-Aldrich) solution in water and dislodging conidia of a 7-dayold culture of $A$. rabie $i$ with a sterile glass rod. The concentration of the conidial suspension for each isolate was determined with the aid of a hemacytometer, adjusted to $2 \times 10^{5} \mathrm{conidia} / \mathrm{ml}$, and $100 \mu \mathrm{l}$ of the suspension was pipetted onto each of two replicate petri plates $(60 \times 15 \mathrm{~mm})$. Plates were incubated at $20^{\circ} \mathrm{C}$ for $18 \mathrm{~h}$ in the dark, and subsequently examined at $\times 100$ magnification under a compound microscope. Percent germination was recorded for at least 100 conidia per isolate. A conidium was considered germinated if the germ tube was at least as long as the conidium (33). Percent conidial germination was converted into percent inhibition calculated as $100-[(\%$ germination of fungicide-amended media/mean $\%$ germination of nonamended control $) \times 100$ ]. From this, $\mathrm{EC}_{50}$ values (the fungicide concentration that inhibits conidial germination by $50 \%$ of the nonamended control) for each isolate were calculated using a linear interpolation method $(23,24,33)$. The resistance factor of individual isolates relative to sensitive isolates was calculated by dividing the $\mathrm{EC}_{50}$ value of individual isolates by the mean $\mathrm{EC}_{50}$ values of the baseline population to azoxystrobin $(0.0272 \mu \mathrm{g} / \mathrm{ml})$ and pyraclostrobin $(0.0023 \mu \mathrm{g} / \mathrm{ml})(33)$.

A. rabiei isolates were tested in groups with 5 to 12 isolates per group. In each group, at least one internal control isolate was included to ensure assay reproducibility $(23,24,33,34,36)$. In the in vitro fungicide sensitivity trials conducted on $2005 \mathrm{~A}$. rabiei isolates, a known QoI-sensitive isolate (AR666) was selected from the previously established baseline (33) to serve as an internal control; for those collected in 2006 and 2007, a QoI-resistant internal control isolate (06BWEF2-46) was also included. The internal controls were tested in five separate trials as described above, and the mean, standard error, and 95\% confidence intervals were calculated based on the resulting $\mathrm{EC}_{50}$ values $(33,34,36)$. If the internal control isolate $\mathrm{EC}_{50}$ values were within the previously determined $95 \%$ confidence intervals, trials were combined for statistical analysis. Only trials that satisfied the assay reproducibility requirements were included in analysis. Isolates were combined into a single experiment by year of isolate collection. Isolate $\mathrm{EC}_{50}$ values were analyzed using the general linear models (PROC GLM) in SAS (version 9.1, SAS institute, Inc., Cary, NC), following a completely randomized design. The experiment was repeated, and $F$ tests were conducted to determine if variances were homogeneous $(P \leq 0.05)$ between experiments. Correlation analysis was performed on $\mathrm{EC}_{50}$ values for azoxystrobin and pyraclostrobin using Pearson's correlation coefficient (PROC CORR). Mean $\mathrm{EC}_{50}$ values were compared using Fisher's protected least significant difference (LSD) test $(\alpha=0.05)$.

Establishment of a discriminatory dose system. Preliminary experiments to determine a discriminatory dose for screening A. rabiei fungicide sensitivity using azoxystrobin-amended media prepared at concentrations of $0,0.1$, and 1 $\mu \mathrm{g} / \mathrm{ml}$ with $100 \mu \mathrm{g} / \mathrm{ml}$ SHAM were established as described above. A. rabiei isolates were prepared for testing and evaluated for percent germination as described above. Results of these experiments demonstrated that spore germination of sensitive isolates is completely inhibited at fungicide concentrations of $1 \mu \mathrm{g} / \mathrm{ml}$, but resistant isolates had greater than $50 \%$ germination at the same fungicide concentration (data not shown). Based on these results, a discriminatory dose of $1 \mu \mathrm{g} / \mathrm{ml}$ of azoxystrobin was selected for testing an additional 22 isolates from 2006, and 283 isolates from 2007 for in vitro QoI fungicide sensitivity. Isolates were tested as described above in nine groups with 35 to 50 isolates per group. The internal control isolates previously tested were included in each group. Isolates were considered resistant to azoxystrobin if germination was greater than $50 \%$ at the discriminatory dose. Thirty arbitrarily selected isolates from 2007 were tested for azoxystrobin sensitivity using both the discriminatory dose method, and by calculating $\mathrm{EC}_{50}$ values using the procedures described above. This was done to validate discriminatory dose results by determining if isolates with high $\mathrm{EC}_{50}$ values had high germination rates on the discriminatory dose. The experiment was repeated, and percent germination values for each isolate were examined for statistical measures of dis- persion and normality using PROC UNIVARIATE of SAS. Due to skewed, nonnormal distributions of values, data were arcsine transformed and re-examined for normality. Because of the nature of the fungicide sensitivity response, transformation of percent values did not reduce skew, and distributions of discriminatory dose data were compared using the Kolmogorov-Smirnov two-sample test in SAS.

Effect of $A$. rabiei fungicide sensitivity on disease control on chickpea. Greenhouse trials were performed to determine the level of in vivo disease control attainable with QoI fungicides against isolates with differing QoI-sensitivities based on in vitro tests. Two QoI-sensitive A. rabiei isolates (JB9-5 and SHRF12) and three QoI-resistant isolates (BMXQ65, DF8, and H201-6) were included in the trial. QoI sensitivity of these five isolates was determined using the discriminatory dose of 1 $\mu \mathrm{g} / \mathrm{ml}$ azoxystrobin described above. Conidia of each of the three QoI-resistant isolates had over $95 \%$ germination on the discriminatory dose of $1 \mu \mathrm{g} / \mathrm{ml}$, while conidia germination of the two sensitive isolates was completely inhibited at the same dose (data not shown).

Methods established by Pasche et al. $(23,24)$ were used as a basis for performing greenhouse experiments. Briefly, chickpea seeds (cv. Burpee) were sown in 473-ml plastic cups filled with Sunshine Mix 1 (Sun Gro Horticulture Inc., Bellevue, WA) and grown under 400 watt highpressure sodium lamps set for an 18-h photoperiod, at $22 \pm 2{ }^{\circ} \mathrm{C}$. Ten to 14 days after planting, chickpea plants were treated with commercial formulations of azoxystrobin (Quadris 2.08 SC; Syngenta Crop Protection) or pyraclostrobin (Headline, 2.09 EC; BASF Corporation) at concentrations of $0,0.1,1.0,10$, and $100 \mu \mathrm{g}$ a.i. $/ \mathrm{ml}$ of water. Fungicides were applied to runoff using a $\mathrm{CO}_{2}$-powered hand-held sprayer. Approximately $24 \mathrm{~h}$ after fungicides were applied, plants were inoculated with $A$. rabiei conidial suspensions prepared from 14-day-old cultures of selected sensitive and resistant isolates. Suspensions were adjusted to a concentration of $3 \times 10^{5} \mathrm{co}-$ nidia/ml and applied to chickpea plants within an hour after preparation. Inoculum from each isolate was applied to plants using a hand-held airbrush paint sprayer connected to a vacuum pump (Welch DryFast Vacuum Pump, Gardner Denver Inc., Niles, IL). Chickpea plants were placed in separate mist chambers by isolate and held at $>95 \%$ relative humidity for $36 \mathrm{~h}$ at a 16$\mathrm{h}$ photoperiod under artificial lighting before being placed in enclosed chambers on greenhouse benches. Chambers were constructed with 1-m-high polyethylene plastic barriers between plants inoculated with different isolates to reduce the potential for cross-contamination. After 10 days, disease severity for plants was visually assessed as the percent area infected of 
whole plant. The experiment was designed as a randomized complete block (RCB) with a split-plot arrangement. Isolate was considered as the whole plot factor and a factorial arrangement of fungicides and fungicide concentrations as the subplot. All main effects were considered fixed for the purpose of testing significance. Three replicates were included in each experiment, and the average disease severity was calculated for two plants from each experimental unit. Percent disease control was calcu-

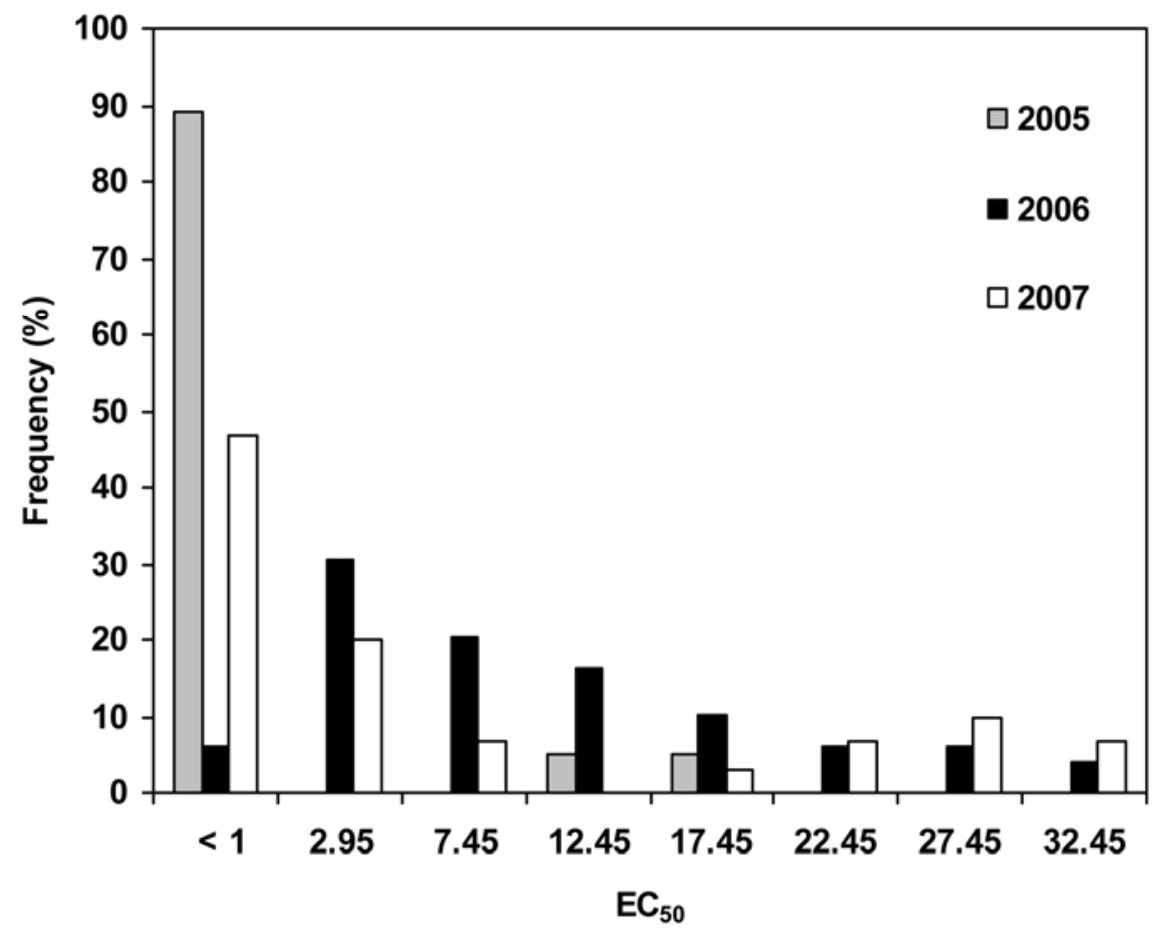

Fig. 1. Frequency distributions of effective fungicide concentrations that inhibited spore germination by $50 \%\left(\mathrm{EC}_{50}\right.$ value; $\left.\mu \mathrm{g} / \mathrm{ml}\right)$ for Ascochyta rabiei isolates to azoxystrobin in $2005(n=19), 2006(n=$ $49)$, and $2007(n=30)$. Individual isolates are grouped in class intervals of $4.9 \mu \mathrm{g} / \mathrm{ml}$; values on the $\mathrm{x}$ axis indicate the midpoint of the interval.

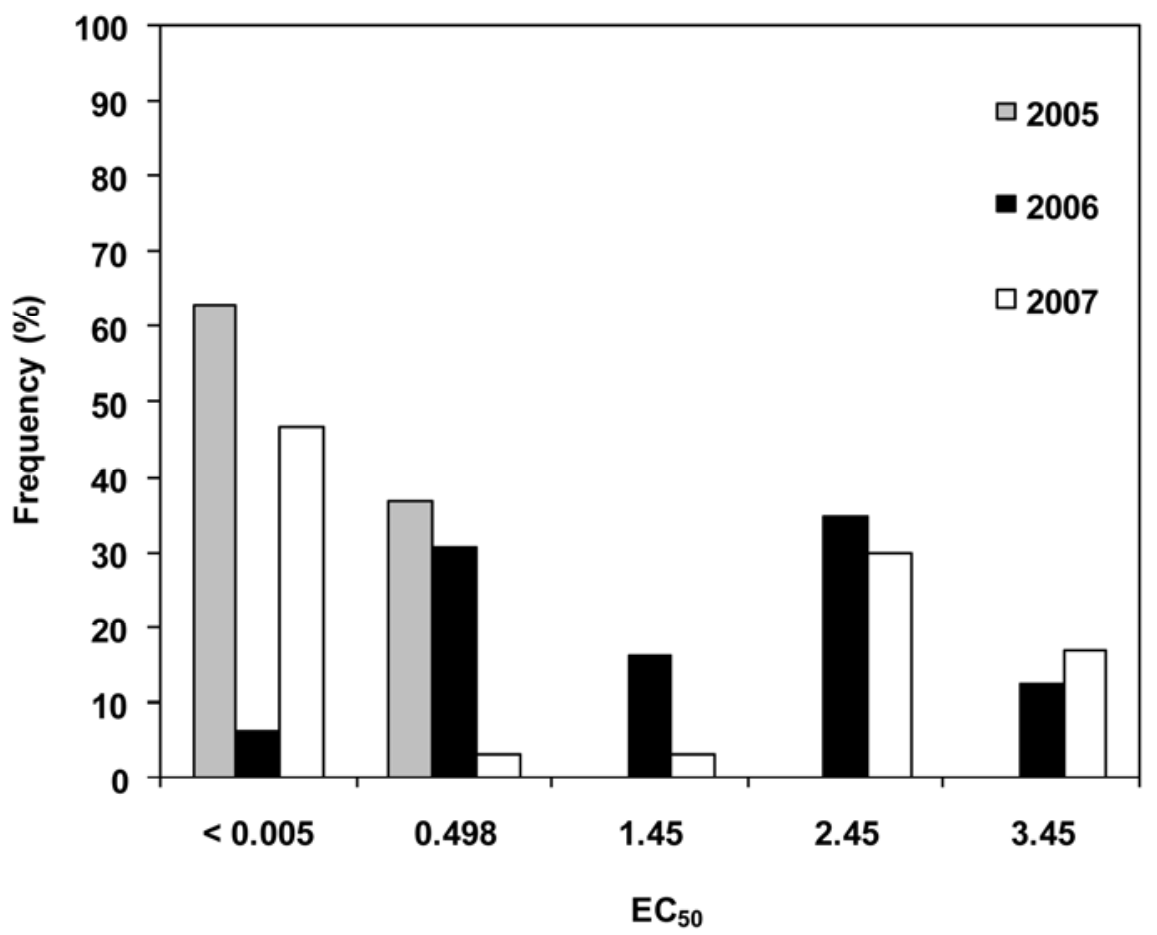

Fig. 2. Frequency distributions of effective fungicide concentrations that inhibited spore germination by $50 \%\left(\mathrm{EC}_{50}\right.$ value; $\left.\mu \mathrm{g} / \mathrm{ml}\right)$ for Ascochyta rabiei isolates to pyraclostrobin in $2005(n=19), 2006(n=$ $49)$, and $2007(n=30)$. Individual isolates are grouped in class intervals of $0.9 \mu \mathrm{g} / \mathrm{ml}$; values on the $\mathrm{x}-$ axis indicate the midpoint of the interval.

lated by: $[1-(\%$ diseased tissue $/ \%$ disease on $0 \mu \mathrm{g} / \mathrm{ml}$ control $)] \times 100$. The experiment was repeated, and $F$ tests were conducted to determine if variances were homogeneous between the two greenhouse experiments. Data were converted to percent disease control to facilitate direct comparisons between sensitive and resistant isolates, and analyzed using PROC GLM in SAS. Mean percent disease severity and control were compared using Fisher's protected LSD test $(\alpha=0.05)$.

\section{RESULTS}

In vitro fungicide sensitivity assay. Independent analyses of variance of in vitro fungicide sensitivity experiments for pyraclostrobin and azoxystrobin $\mathrm{EC}_{50}$ values determined that error variances were homogenous $(P=0.05)$; thus, experiments were combined for further analysis. Frequency distributions of 19 A. rabiei isolates collected in 2005 demonstrated that 89 and $63 \%$ of isolates had $\mathrm{EC}_{50}$ values of less than $1 \mu \mathrm{g} / \mathrm{ml}$ and $0.005 \mu \mathrm{g} / \mathrm{ml}$ for azoxystrobin and pyraclostrobin, respectively (Figs. 1 and 2). These isolates were considered to be sensitive to the fungicides tested, and $\mathrm{EC}_{50}$ values of these isolates were comparable to previously established baseline values of $0.0272 \mu \mathrm{g} / \mathrm{ml}$ for azoxystrobin and $0.0023 \mu \mathrm{g} / \mathrm{ml}$ for pyraclostrobin (33). $\mathrm{EC}_{50}$ values for two 2005 isolates were well outside the range established by the baseline; they exhibited a 539-fold decrease in sensitivity to azoxystrobin and a 704-fold decrease in sensitivity to pyraclostrobin when compared to the mean sensitivity of baseline isolates. Conversely, in 2006 and 2007, 93.7 and $53.1 \%$ of $A$. rabiei isolates were determined to have $\mathrm{EC}_{50}$ values greater than 1 $\mu \mathrm{g} / \mathrm{ml}$ and $0.005 \mu \mathrm{g} / \mathrm{ml}$ for azoxystrobin and pyraclostrobin, respectively (Figs. 1 and 2). Correlation analysis revealed a positive association between azoxystrobin and pyraclostrobin $\mathrm{EC}_{50}$ values $(r=0.66, P$ $<0.001, n=98$ ) (Fig. 3).

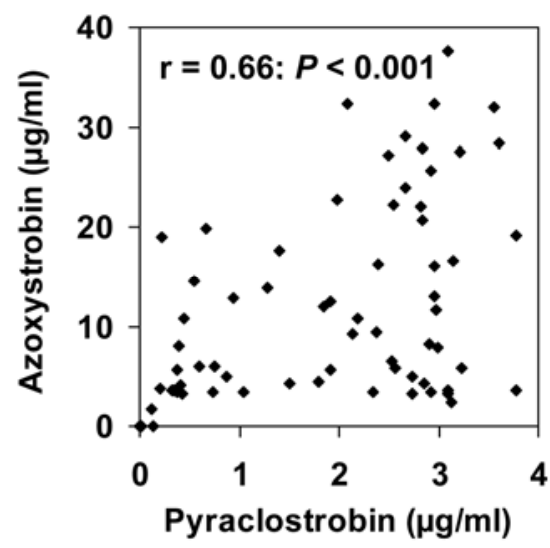

Fig. 3. Relationship between in vitro mean effective fungicide concentration that inhibited spore germination by $50 \%\left(\mathrm{EC}_{50}\right.$ value; $\left.\mu \mathrm{g} / \mathrm{ml}\right)$ for azoxystrobin and pyraclostrobin sensitivity of 98 Ascochyta rabiei isolates from 2005 to 2007. 
Establishment of a discriminatory dose. Comparison of distributions of percent germination on the discriminatory dose of $1 \mu \mathrm{g} / \mathrm{ml}$ by the KolmogorovSmirnov two-sample test showed no significant differences between experiments $(K S a=1.143, P=0.1466)$. The selected discriminatory dose of $1.0 \mu \mathrm{g} / \mathrm{ml}$ azoxystrobin was effective in determining the in vitro fungicide sensitivity of 30 isolates of $A$. rabiei from 2007 when compared to $\mathrm{EC}_{50}$ values generated for the same isolates, and a clear differential response in conidial germination was observed be-

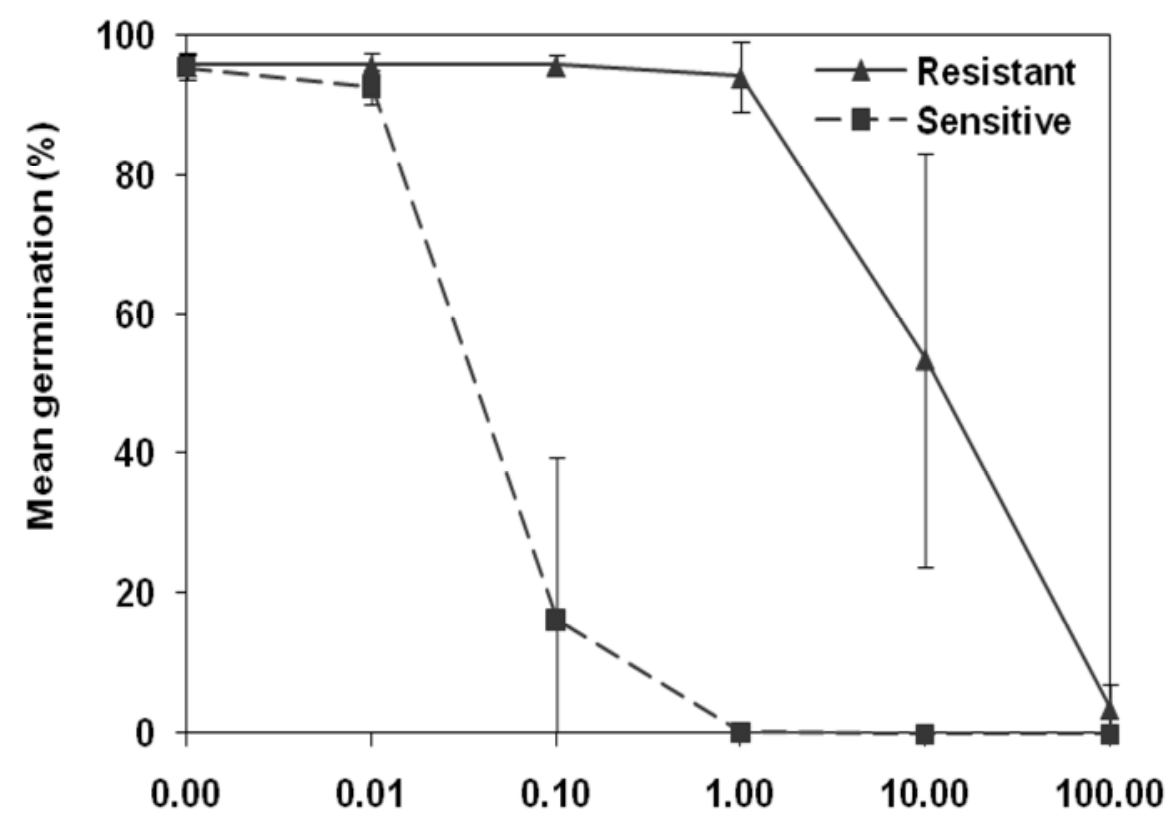

Fungicide concentration $(\mu \mathrm{g} / \mathrm{ml})$

Fig. 4. Mean in vitro sensitivity of 16 QoI-resistant (-) and 14 QoI-sensitive (- - -) Ascochyta rabiei isolates from 2007 measured as mean percent germination on azoxystrobin-amended media at different fungicide concentrations $(\mu \mathrm{g} / \mathrm{ml})$ for determination of a discriminatory dose. Values include standard errors of percent germination.

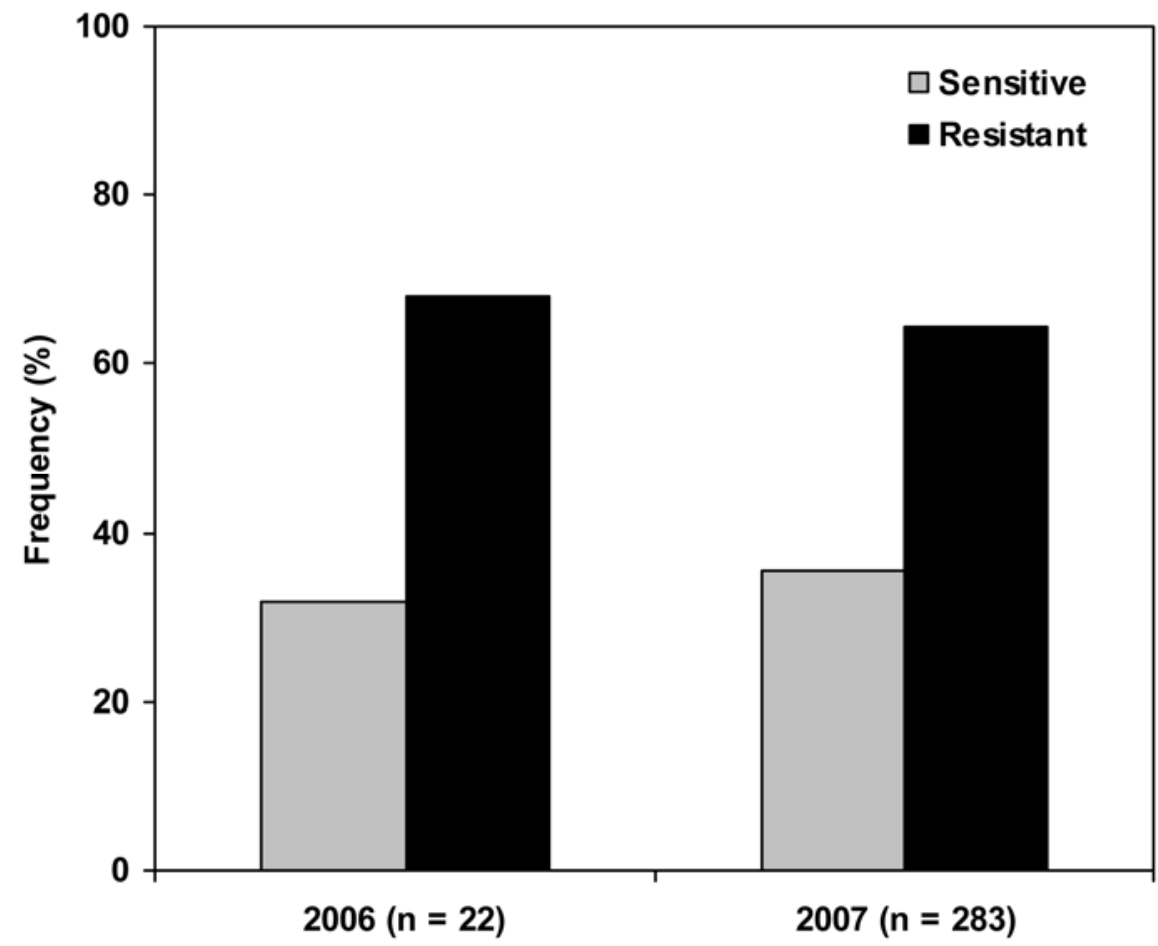

Fig. 5. Frequency of QoI-sensitive and resistant Ascochyta rabiei isolates in the Northern Great Plains as determined by a discriminatory dose of $1 \mu \mathrm{g} / \mathrm{ml}$ of azoxystrobin-amended media for isolates collected in $2006(n=22)$ and $2007(n=283)$. tween QoI-resistant and -sensitive isolates (Fig. 4). Sixteen isolates with resistance factors of approximately 100 -fold had a mean germination of $94.0 \%$ in the presence of $1 \mu \mathrm{g} / \mathrm{ml}$ azoxystrobin (Fig. 4). QoIsensitive control isolates had less than $3 \%$ conidial germination on the discriminatory dose, with a mean of $0.3 \%$ conidial germination (Fig. 4). Discriminatory dose data from the 305 isolates collected in 2006 and 2007 determined that the frequency of azoxystrobin resistance in $A$. rabiei was over $60 \%$ in each year. These results are similar to the frequencies determined by $\mathrm{EC}_{50}$ values generated for isolates collected in those same years (Fig. 5).

QoI-resistant isolates (determined by $\mathrm{EC}_{50}$ values or discriminatory dose measurements) were present in only one of three counties sampled in North Dakota in 2005, in all seven counties sampled in 2006, and in seven of eight counties sampled in 2007. QoI-resistant isolates were detected in four of five counties sampled in Montana in 2007 (Tables 1 and 2).

Effect of $A$. rabiei fungicide sensitivity on disease control on chickpea. Independent analysis of disease control experiments determined that variances were homogenous, and experiments were combined for further analysis. Significant interactions were observed between the whole plot (isolate) and subplot factors (fungicide and fungicide concentration) $(P$ $<0.001$ ), as well as between the subplot factors of fungicide and fungicide concentration $(P<0.001)$ for percent disease severity and percent disease control of fungicides on Ascochyta blight-infected chickpea. Significant effects $(P<0.001)$ were also observed for isolate, fungicide, and level of fungicide concentration for both percent disease severity and percent disease control.

Disease severity was significantly greater on plants inoculated with QoIresistant isolates at all concentrations of azoxystrobin and pyraclostrobin, including the nontreated control $(0 \mu \mathrm{g} / \mathrm{ml})$. QoIsensitive isolates were completely controlled at concentrations of 10 and 100 $\mu \mathrm{g} / \mathrm{ml}$ azoxystrobin and pyraclostrobin (Figs. 6 and 7). Disease control of QoIresistant isolates was significantly reduced for azoxystrobin and pyraclostrobin when compared to QoI-sensitive isolates at all fungicide concentrations (Fig. 7). Pyraclostrobin provided significantly greater disease control of QoI-resistant isolates at concentrations of $100 \mu \mathrm{g} / \mathrm{ml}$ when compared to azoxystrobin. However, pyraclostrobin provided less than $65 \%$ disease control of QoI-resistant isolates, while $100 \%$ disease control of sensitive isolates was achieved at the same concentration (Fig. 7).

\section{DISCUSSION}

Resistance to QoI fungicides was observed in isolates of $A$. rabiei in North 
Dakota in all years of collection and in Montana in 2007. In this study, only two A. rabiei isolates from one county were considered to be QoI-resistant in 2005, while in 2006 and 2007, QoI-resistant isolates were present at a higher frequency than sensitive isolates, and resistance was widespread across the sampling locations in North Dakota. With the continued application of QoI fungicides, it would not be expected for the frequency of resistant isolates to decrease slightly from 2006 to 2007, but differences among years can most likely be explained by the increase in the numbers of samples and sampling locations from 2006 to 2007.

When the monitoring program was established in 2005, isolates were available from a limited number of locations. Fungicide sensitivity monitoring was expanded in 2006 and 2007 to include a greater number of isolates from grower locations, which provided a more complete sensitivity distribution of the A. rabiei population in these areas. If the frequency of resistant isolates in a population is low at a given time and location, it is likely that a large number of isolates will need to be tested to detect fungicide resistance, especially if a loss in disease control has not been observed with a fungicide (26). Subsequently, it is difficult to determine if a pathogen population is truly sensitive to fungicides based on the $\mathrm{EC}_{50}$ values of one or a few isolates from a location, and we cannot accurately state that fungicide resistance did not exist in some locations sampled in the Northern Great Plains and the Pacific Northwest, since only a few samples were available for testing. This reinforces the need for adequate sample numbers in fungicide sensitivity monitoring programs, so that determination of isolate sensitivity, and consequently disease management recommendations, are based on adequate and representative data.

QoI sensitivity evaluations via the generation of $\mathrm{EC}_{50}$ values from percent conidial germination is considered to be a reliable and established method for determining fungicide sensitivity $(24,35)$ and was utilized to develop the previously described baseline for A. rabiei to QoI fungicides (33). However, these methods are very time-consuming, especially considering the large number of samples that must typically be examined to detect the true level of resistance in a pathogen population (26). Fungicide sensitivity assays using a single discriminatory dose often are utilized where fungicide resistance has been identified in a pathogen population (21,25,34). An effective discriminatory dose is typically a fungicide concentration at which growth of sensitive isolates is mostly or completely inhibited and resistant isolates have greater than $50 \%$ growth. This screening method allows a large number of isolates to be rapidly and accurately assessed for fungicide resistance,
Table 2. Collection information and location of 2006 and 2007 Ascochyta rabiei isolates tested for in vitro QoI fungicide sensitivity using a discriminatory dose of $1 \mu \mathrm{g} / \mathrm{ml}$ azoxystrobin

\begin{tabular}{lccc}
\hline $\begin{array}{l}\text { Collection location } \\
\text { by county }\end{array}$ & $\begin{array}{c}\text { Number of } \\
\text { locations sampled }\end{array}$ & $\begin{array}{c}\text { Total number } \\
\text { of isolates }\end{array}$ & $\begin{array}{c}\text { Isolates with } \\
\text { QoI resistance }\end{array}$ \\
\hline 2006 & & & \\
North Dakota & 1 & 4 & 11 \\
McClean & 2 & 11 & 3 \\
Renville & 1 & 5 & 0 \\
Ward & 1 & 2 & 14 \\
Williams & 5 & 22 & \\
Total & & & 12 \\
2007 & 1 & 12 & 22 \\
North Dakota & 2 & 22 & 17 \\
Adams & 3 & 17 & 27 \\
Burke & 1 & 4 & 8 \\
Divide & 3 & 27 & 16 \\
Hettinger & 2 & 25 & 66 \\
McClean & 1 & 16 & 168 \\
Mountrail & 1 & 144 & \\
Ward & 267 & 2 \\
Williams & 24 & & 2 \\
Total & & 2 & 8 \\
Montana & 1 & 2 & 0 \\
Gallatin & 1 & 9 & 1 \\
Richland & 2 & 2 & 13 \\
Sheridan & 1 & 1 & 16 \\
Valley & 1 & 16 & \\
Yellowstone & 6 & & \\
Total & & & \\
\hline
\end{tabular}

${ }^{a}$ An isolate was considered resistant if mean conidia germination was $>50 \%$ on the discriminatory dose.

A

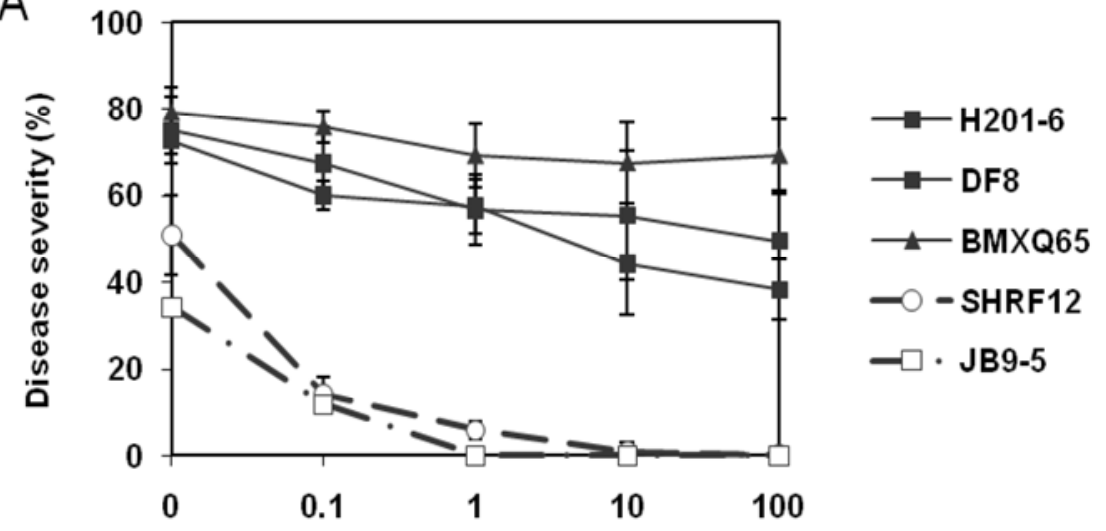

Fungicide concentration ( $\mathrm{gg} / \mathrm{ml})$

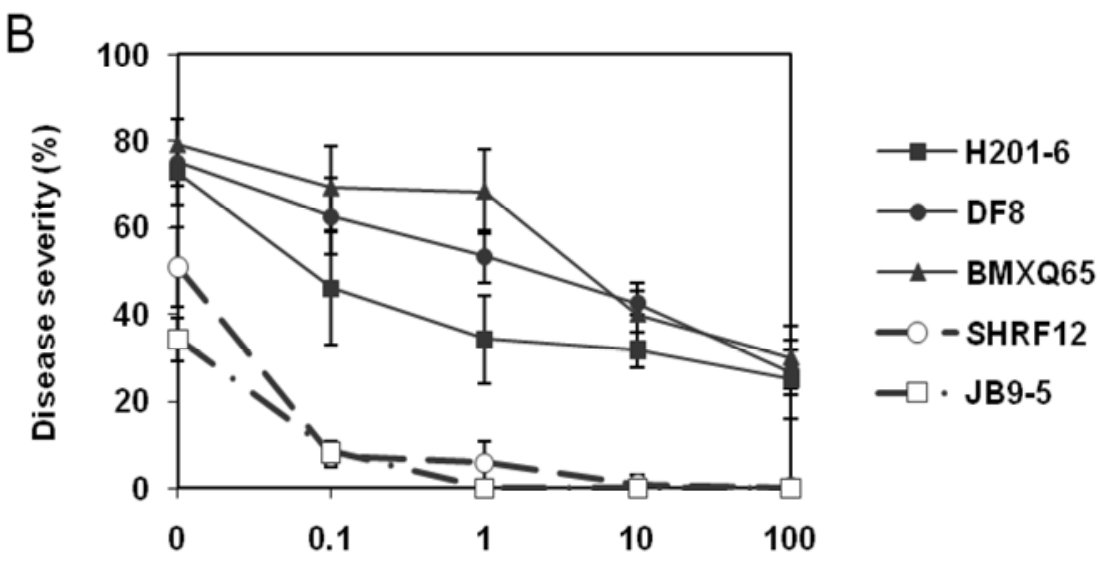

Fungicide concentration $(\mu \mathrm{g} / \mathrm{ml})$

Fig. 6. Mean in vivo percent disease severity for two QoI-sensitive (- - -) and three QoI-resistant (-) Ascochyta rabiei isolates to $\mathbf{A}$, azoxystrobin and $\mathbf{B}$, pyraclostrobin at each fungicide concentration $(\mu \mathrm{g} / \mathrm{ml})$. Values include standard errors of disease control measurements obtained from two plants across three replications. 
and has been used in several pathogen systems $(21,25,34)$. The discriminatory dose of $1 \mu \mathrm{g} / \mathrm{ml}$ was very effective in identifying A. rabiei isolates resistant to azoxystrobin. The development and use of a discriminatory dose fungicide sensitivity assay for azoxystrobin and pyraclostrobin resistance monitoring facilitated the screening of a much larger sample size of the $A$. rabiei population.

Differences in disease control were observed when azoxystrobin and pyraclostrobin were applied to chickpea plants infected with QoI-resistant and QoIsensitive isolates. Applications of azoxystrobin at a concentration of $100 \mu \mathrm{g} / \mathrm{ml}$ provided less than $50 \%$ control of disease on plants infected with QoI-resistant isolates. This level of control is commercially unacceptable, and indicates that in vitro fungicide assays are capable of predicting A. rabiei isolate sensitivity in vivo. Clear differences in disease severity were observed between both QoIsensitive isolates causing significantly less disease on non-fungicide-treated plants as compared to the three QoIresistant isolates used in the study. This suggests that QoI-resistant A. rabiei isolates may have increased aggressiveness compared to QoI-sensitive isolates, possibly providing a competitive advantage in nature. These conclusions are based on a limited number of isolates, however, and additional pathogenicity studies should be conducted on a larger number of QoI-sensitive and -resistant isolates to determine if true differences in aggressiveness exist.

Since no A. rabiei isolates were collected from North Dakota prior to 2005, it cannot be determined if detectable QoI fungicide resistance was present before this time. Despite this, QoI fungicide resistance was detected in under 3 years of registration and use for azoxystrobin and within 2 years for pyraclostrobin. This rapid shift in sensitivity has been observed in several other plant pathogens, including Erysiphe graminis (4), Podosphaera xan-

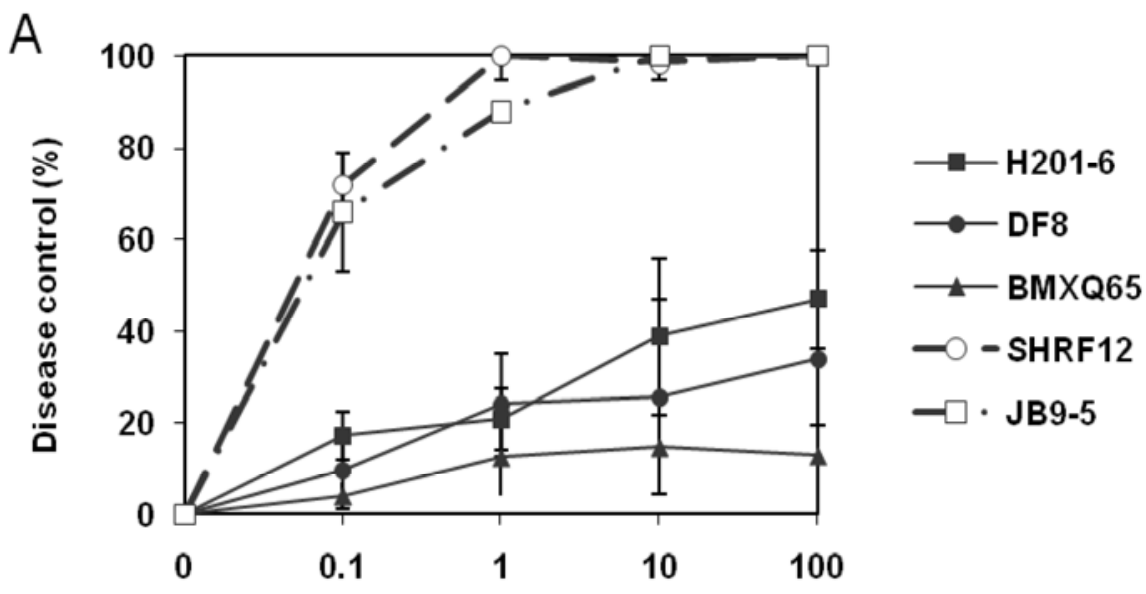

Fungicide concentration $(\mu \mathrm{g} / \mathrm{ml})$

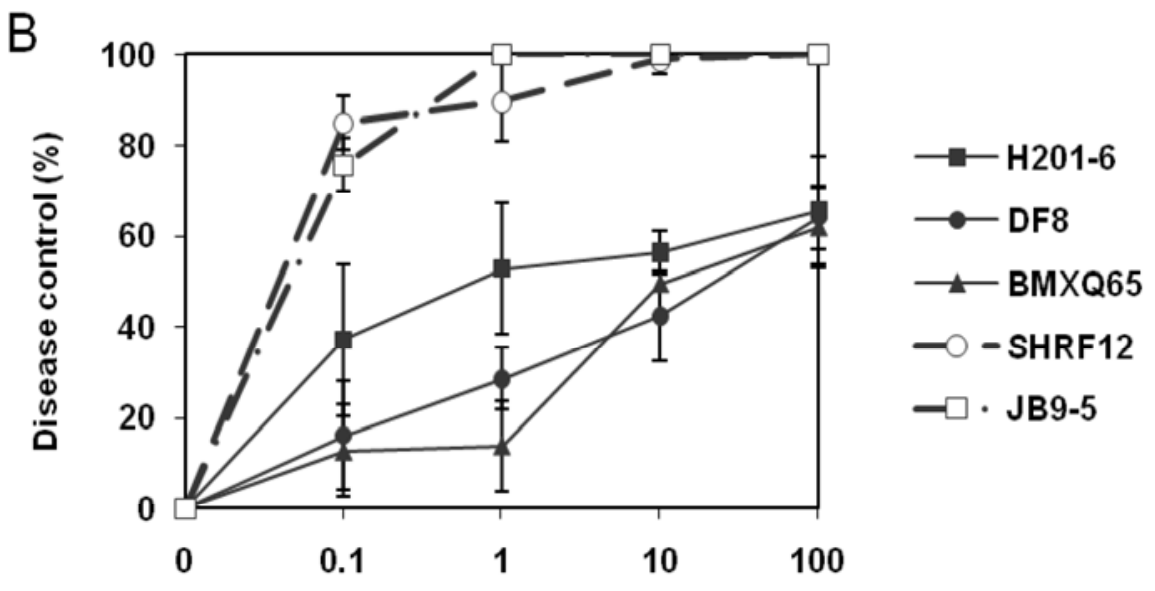

Fungicide concentration $(\mu \mathrm{g} / \mathrm{ml})$

Fig. 7. Mean in vivo percent disease control for two QoI-sensitive (- - -) and three QoI-resistant (-) Ascochyta rabiei isolates to $\mathbf{A}$, azoxystrobin and $\mathbf{B}$, pyraclostrobin at each fungicide concentration $(\mu \mathrm{g} / \mathrm{ml})$. Values include standard errors of disease control measurements obtained from two plants across three replications.

thii (16), Pyricularia grisea (31), Colletotrichum cereale (34), and Didymella bryoniae (28). In each case, resistance to QoI fungicides occurred in two or less years. However, the speed at which resistance to QoI fungicides was expressed in A. rabiei is not necessarily surprising, since curative applications of a single chemical class were applied repeatedly to a pathogen with the potential for high inoculum production and genetic diversity.

QoI resistance in A. rabiei was first reported in Canada in 2004, and in vitro baseline sensitivity of Canadian populations of A. rabiei to pyraclostrobin was reported as $0.25 \mathrm{ppm}$ (7). This value is substantially higher than the sensitivity of A. rabiei baseline populations in the Northern Great Plains $(0.0023 \mu \mathrm{g} / \mathrm{ml})$ (33), and due to methodological differences and different baseline populations it is difficult to compare the results of the Canadian work with those of the current research $(7,15)$. Although it is difficult to ascertain the effect of methodological differences on the detection of QoIresistant phenotypes of $A$. rabiei, it is clear that standardized testing methods using baseline populations, spore germination assays (4), and SHAM (33) are necessary to provide accurate assessments of QoI sensitivity in different chickpea production areas.

Large shifts in magnitude of fungicide sensitivity $(>100 \times)$ and a complete loss of disease control with QoI fungicides are typical of isolates that have developed the G143A mutation conferring QoI fungicide resistance, and is documented in many pathogens $(3,5,6,12,14,16,18,19,34)$. While the specific mutation conferring QoI resistance in A. rabiei has not been determined, greater than $100 \times$ sensitivity shifts were observed in vitro and in our greenhouse fungicide efficacy study. Both azoxystrobin and pyraclostrobin applied at the highest rate $(100 \mu \mathrm{g}$ a.i./ml $)$ did not provide adequate disease control of suspected QoI-resistant isolates. This leads to speculation that the G143A mutation is present in A. rabiei, and indicates that applications of either QoI fungicide to a resistant A. rabiei population may not provide the disease control necessary for a profitable crop. The lack of disease control and magnitude of resistance factors observed with both azoxystrobin and pyraclostrobin with QoI-resistant isolates indicates that cross-resistance to QoI fungicides is observed in A. rabiei on chickpea, and confirms a previous report of in vitro cross-sensitivity (33).

Once the mutation conferring resistance is determined for A. rabiei, allele-specific primers can be designed to distinguish QoI-sensitive isolates from QoI-resistant isolates, and a real-time or quantitative PCR (Q-PCR) assay can be implemented for fungicide resistance monitoring. This method is preferable to screening isolates 
using in vitro spore germination techniques, because it is rapid and accurate, and fungicide sensitivity can be determined for a large number of isolates in a short amount of time. This method would also aid in determining if other resistance genotypes such as the F129L or G137R exist in populations of $A$. rabiei, since these mutations may not be easily observed with a discriminatory dose assay. Q-PCR has been used in fungicide resistance studies in several pathogens $(12,18,23,27)$ and would be a desirable alternative for screening for QoI fungicide sensitivity in $A$. rabiei isolates in the Northern Great Plains.

In response to the results presented here, North Dakota State University recommended that no applications of QoI fungicides be applied to chickpea in North Dakota in 2007. Instead, it was recommended that preventative applications of chlorothalonil or maneb be applied prior to flowering, followed by a rotation of the fungicides boscalid and prothioconazole at flowering, or if conditions were favorable for disease development. Although the DMI and carboximide fungicides are considered to be at a medium risk for developing resistance, fungicide resistance has developed within each of these classes in other pathogens $(1,6)$. Thus, extreme care should be taken to use these fungicides in a manner that prevents further development of A. rabiei fungicide resistance in other fungicide classes. Cross-resistance within fungicide classes limits the potential of new fungicides from the same chemical class for use in chickpea if resistance to one member of that class is already present. Furthermore, recent work in another system has resulted in further complication of resistance development: DMI-resistant isolates of Monilinia fructicola were reported to develop resistance to the QoI fungicide azoxystrobin more quickly than DMI-sensitive isolates (20). This information reinforces the need for fungicide sensitivity monitoring in pathogens such as $A$. rabiei that are predisposed to fungicide resistance due to their biological nature, and are intensively managed with fungicide applications.

Until chickpea cultivars with durable levels of Ascochyta blight resistance are available, fungicide applications for disease management will be essential in the Northern Great Plains. Additional research is needed on the efficacy of new fungicidal compounds and/or different chemical classes on Ascochyta blight to increase the management options available for growers and minimize the selection pressure on the pathogen due to repeated applications of one fungicide class.

\section{ACKNOWLEDGMENTS}

This project was funded by a grant from the United States Department of Agriculture - Cooperative State Research, Education, and Extension Service (USDA-CSREES) Cool Season Food
Legume Research Program. We thank C. Doetkott for statistical consultation; N. Anderson, R. Benz, D. Liane, I. Mallik, D. Peterson, R. Sherman, and B. Tarang for technical assistance; and BASF Corporation and Syngenta Crop Protection for providing the technical grade formulations of the fungicides.

\section{LITERATURE CITED}

1. Avenot, H. F., and Michailides, T. J. 2007. Resistance to boscalid fungicide in Alternaria alternata isolates from pistachio in California. Plant Dis. 91:1345-1350.

2. Avenot, H., Morgan, D. P., and Michailides, T. J. 2008. Resistance to pyraclostrobin, boscalid, and multiple resistance to Pristine ${ }^{\circledR}$ (pyraclostrobin + boscalid) fungicide in Alternaria alternata causing Alternaria late blight of pistachios in California. Plant Pathol. 57:135-140.

3. Avila-Adame, C., Olaya, G., and Koller, W. 2003. Characterization of Colletotrichum graminicola isolates resistant to strobilurinrelated QoI fungicides. Plant Dis. 87:14261432.

4. Bartlett, D. W., Clough, J. M., Godwin, J. R., Hall, A. A., Hamer, M., and Parr-Dobrzanski, B. 2002. The strobilurin fungicides. Pest Manage. Sci. 58:649-662.

5. Brasseur, G., Sami Saribas, A., and Daldal, F. 1996. A compilation of mutations located in the cytochrome $b$ subunit of the bacterial and mitochondrial $b c_{1}$ complex. Biochim. Biophys. Acta 1275:61-69.

6. Brent, K. J., and Holloman, D. W. 2007. Fungicide resistance: The assessment of risk. 2nd ed. Fungicide Resistance Action Committee. Crop Life, Brussels, Belgium.

7. Chang, K. F., Ahmed, H. U., Hwang, S. F., Gossen, B. D., Strelkov, S. E., Blade, S. F., and Turnbull, G. D. 2007. Sensitivity of field populations of Ascochyta rabiei to chlorothalonil, mancozeb, and pyraclostrobin fungicides, and effects of strobilurin fungicides on the progress of Ascochyta blight of chickpea. Can. J. Plant Sci. 87:937-944.

8. Chen, W., Coyne, C., Peever, T., and Muehlbauer, F. 2004. Characterization of chickpea differentials for pathogenicity assay of Ascochyta blight and identification of chickpea accessions resistant to Didymella rabiei. Plant Pathol. 53:759-769.

9. Chin, K. M., Wirz, M., and Laird, D. 2001. Sensitivity of Mycosphaerella fijiensis from banana to trifloxystrobin. Plant Dis. 85:12641270.

10. Chongo, G., Gossen, B. D., Buchwaldt, L., Adhikari, T., and Rimmer, S. R. 2004. Genetic diversity of Ascochyta rabiei in Canada. Plant Dis. 88:4-10.

11. Davidson, J. A., and Kimber, R. B. E. 2007. Integrated disease management of Ascochyta blight in pulse crops. Eur. J. Plant Pathol. 119:99-110.

12. Fraaije, B. A., Butters, J. A., Coelho, J. M., Jones, D. R., and Holloman, D. W. 2002. Following the dynamics of strobilurin resistance in Blumeria graminis f.sp. tritici using quantitative allele-specific real-time PCR measurements with the fluorescent dye SYBR green I. Plant Pathol. 51:45-54.

13. Gan, Y. T., Siddique, K. H. M., MacLeod, W. J., and Jayakumar, P. 2006. Management options for minimizing the damage by Ascochyta blight (Ascochyta rabiei) in chickpea (Cicer arietinum L.). Field Crops Res. 97:121-134.

14. Gisi, U., Sierotzke, H., Cook, A., and McCaffery, A. 2002. Mechanisms influencing the evolution of resistance to Qo inhibitor fungicides. Pest Manage. Sci. 58:859-867.

15. Gossen, B. D., and Anderson, K. L. 2004. First report of resistance to strobilurin fungicides in Didymella rabiei. (Abstr.) Can. J. Plant Pathol. 26:404
16. Ishii, H., Fraaije, B. A., Sugiyama, T., Noguchi, K., Nishimura, K., Takeda, T., Amano, T., and Hollomon, D. W. 2001. Occurrence and molecular characterization of strobilurin resistance in cucumber powdery mildew and downy mildew. Phytopathology 91:1166-1171.

17. Kaiser, W. J. 1997. Inter- and intranational spread of Ascochyta pathogens of chickpea, faba bean, and lentil. Can. J. Plant Pathol. 19:215-224.

18. Kianianmomeni, A., Schwarz, G., Felsenstein, F. G., and Wenzel, G. 2007. Validation of a real-time PCR for the quantitative estimation of a G143A mutation in the cytochrome $b c_{1}$ gene of Pyrenophora teres. Pest Manage. Sci. 63:219-224.

19. Kim, Y. S., Dixon, E. W., Vincelli, P., and Farman, M. L. 2003. Field resistance to strobilurin (QoI) fungicides in Pyricularia grisea caused by mutations in the mitochondrial cytochrome $b$ gene. Phytopathology 93:891-900.

20. Luo, C., and Schnabel, G. 2008. Adaptation to fungicides in Monilinia fructicola isolates with different fungicide resistance phenotypes. Phytopathology 98:230-238.

21. Mondal, S. N., Bhatia, A., Shilts, T., and Timmer, L. W. 2005. Baseline sensitivities of fungal pathogens of fruit and foliage of citrus to azoxystrobin, pyraclostrobin, and fenbuconazole. Plant Dis. 89:1186-1194.

22. Nene, Y. L., and Reddy, M. V. 1987. Chickpea diseases and their control. Pages 233-270 in: The Chickpea. M. C. Saxena and K. B. Singh, eds. CAB International, Oxon, UK.

23. Pasche, J. S., Piche, L. M., and Gudmestad, N. C. 2005 . Effect of the F129L mutation in $\mathrm{Al}$ ternaria solani on fungicides affecting mitochondrial respiration. Plant Dis. 89:269-278.

24. Pasche, J. S., Wharam, C. M., and Gudmestad, N. C. 2004. Shift in sensitivity of Alternaria solani in response to QoI fungicides. Plant Dis. 88:181-187.

25. Rebollar-Alviter, A., Madden, L. V., Jeffers, S. N., and Ellis, M. A. 2007. Baseline and differential sensitivity to two QoI fungicides among isolates of Phytophthora cactorum that cause leather rot and crown rot on strawberry. Plant Dis. 91:1625-1637.

26. Russell, P. E. 2004. Sensitivity baselines in fungicide resistance research and management. 2nd ed. Fungicide Resistance Action Committee. Crop Life, Brussels, Belgium.

27. Sierotzki, H., Frey, R., Wullschleger, J., Palermo, S., Karlin, S., Godwin, J., and Gisi, U. 2007. Cytochrome b gene sequence and structure of Pyrenophora teres and P. tritici repentis and implications for $\mathrm{QoI}$ resistance. Pest. Manage. Sci. 63:225-233.

28. Stevenson, K. L., Langston, D. B., Jr., and Seebold, K. W. 2004. Resistance to azoxystrobin in the gummy stem blight pathogen documented in Georgia. Online. Plant Health Progress doi:10.1094/PHP-2004-1207-01RS.

29. Tivoli, B., and Banniza, S. 2007. Comparison of the epidemiology of Ascochyta blights on grain legumes. Eur. J. Plant Pathol. 119:5976.

30. Udupa, S. M., Weigand, F., Saxena, M. C., and Kahl, G. 1998. Genotyping with RAPD and microsatellite markers resolves pathotype diversity in the Ascochyta blight pathogen of chickpea. Theor. Appl. Genet. 97:299-307.

31. Vincelli, P., and Dixon, E. 2002. Resistance to QoI (strobilurin-like) fungicides in isolates of Pyricularia grisea from perennial ryegrass. Plant Dis. 86:235-240.

32. Wise, K., Bradley C., Henson B., McKay, K., Chen, W., and Dugan, F. 2006. Pathotypes and fungicide sensitivity levels of Ascochyta rabiei isolates in the United States. (Abstr.) Proc. Int. Ascochyta Workshop Grain Legumes, 1st. Le Tronchet, France. p. D-3.

33. Wise, K. A., Bradley, C. A., Pasche, J. S. 
Gudmestad, N. C., Dugan, F. M., and Chen, W. 2008. Baseline sensitivity of Ascochyta rabiei to azoxystrobin, pyraclostrobin, and boscalid. Plant Dis. 92:295-300.

34. Wong, F. P., Midland, S. L., and de la Cerda, K. A. 2007. Occurrence and distribution of
QoI-resistant isolates of Colletotrichum cereale from annual bluegrass in California. Plant Dis. 91:1536-1546.

35. Wong, F. P., and Wilcox, W. F. 2000. Distribution of baseline sensitivities to azoxystrobin among isolates of Plasmopara viticola. Plant
Dis. 84:275-281.

36. Wong, F. P., and Wilcox, W. F. 2002. Sensitivity to azoxystrobin among isolates of Uncinula necator: Baseline distribution and relationship to myclobutanil sensitivity. Plant Dis. 86:394404. 